\title{
Staff's Practice of Peer Assessment in the International Classroom in UK HE
}

\author{
Meng Fan ${ }^{1,2}$ \\ ${ }^{1}$ School of Foreign Languages, Fuzhou University, Fuzhou, China \\ ${ }^{2}$ Center for Cross-Cultural Discourse Study, Fuzhou University, Fuzhou, China
}

Email address:

qadata@sina.com

\section{To cite this article:}

Meng Fan. Staff's Practice of Peer Assessment in the International Classroom in UK HE. Science Journal of Education. Vol. 5, No. 3, 2017, pp. 123-128. doi: 10.11648/j.sjedu.20170503.19

Received: March 12, 2017; Accepted: April 27, 2017; Published: May 4, 2017

\begin{abstract}
Influenced by social constructivism emphasizing students' responsibility for their own learning, peer assessment has become popular in many UK universities, which facilitates inquiry into learning by the learner through integration of understanding from active engagement in assessment and collaboration with staff and classmates [1]. As increasingly large numbers of international students come to study in the UK, staff have had to face issues of how to provide an appropriate assessment experience for them. Hence, how to inspire students' performance of peer assessment and make it effective in the international classroom is a challenge for staff. This paper is part of a project studying on international students' perceptions and experience of peer assessment. In this paper, we particularly discuss practice of peer assessment from staff's point of view in relation to internationalization of curriculum and pedagogy in UK HE, by employing a case study methodology complemented by observation in the teaching sessions and interviews with staff in a UK university. The research would contribute to a better understanding of peer assessment in the international classroom in UK HE from staff's perspective, and in turn to an enhancement of pedagogical approaches and assessment innovation.
\end{abstract}

Keywords: Peer Assessment, Formative Assessment, Internationalization, Classification, Framing

\section{Introduction}

Educational researchers advocate that we need new ways of teaching, learning and assessment to internationalize the curriculum, and we need to rethink and design the curriculum in relation to future global employment [2-3], but the extent to which staff understand and reflect on these strategies in practice is undefined. With regard to assessment in UK HE, the change from traditional to innovative assessment approaches has been shown in assessment policy and literature. However, what needs to be determined is the extent to which assessment reform is reflected in staff practices, and how staff can best do to foster intercultural learning through assessment. Moreover, internationalization is among many universities' key strategies, but Robson points out that educational institutions will not become internationalized readily without staff commitment [4]. Since assessment is a necessary feature of HE [5] and the nature of assessment influences the approaches which students adopt for learning [6], it is valuable to investigate staff perceptions and experience of assessment in relation to internationalizing the curriculum.

A variety of innovative assessment approaches for learning has been developed, such as portfolios, peer assessment (PA), and self-assessment [7]. Through involving students in marking and/or feedback on the work of other students, PA has the potential to engage students in assessment in order to make a fundamental contribution to students' personal development [8]. We suggest that PA can be an approach to internationalize the curriculum, as it provides an opportunity for students to participate in the assessment process through evaluating the work of their peers' and acquiring new knowledge about other cultures and countries through open discussion [9]. This paper is part of our project on international students' (ISs') perceptions and experiences of PA, aiming to discuss practice of PA in the international classroom from staff perspective. 


\section{Methods}

In Evan's review of studies on assessment feedback in HE, $80 \%$ are case studies. Our case study of ISs' perceptions and experience of PA in a UK university used qualitative dominate mixed methods [10], but for staff data which is part of our project, qualitative observation of teaching sessions and staff interviews were conducted. Five teaching staff from different modules (Business, Education, Chemical Engineering and Computer Science), one assessment policy maker and one staff educator participated in the individual interviews.

\section{Results}

Students pay close attention to assessment designed and implemented by staff, as it determines students' academic progress in HE [11] Therefore, it is valuable to investigate staff practices of assessment and how to avail assessment as a tool for helping students learning (ibid). Moreover, there is evidence that staff attitudes and expertise about assessment influence the use of assessment approaches and feedback provided to students [12]. Thereby, the study interviewed five teaching staff, one university assessment policy maker and one staff educator to investigate: (a) staff beliefs about teaching, learning and assessment in the international classroom, and (b) staff recognitions of revised assessment policy in relation to university's agenda of creating an internationalized educational setting. The use of PA in the five modules is described in table 1 and 2 .

Four module leaders and one teaching assistant from two faculties at this university participated in staff interviews. Three were from HASS (Faculty of Humanities and Social Sciences), including one from the Business School (BUSI) and two from the Education department (EDUA and EDUB); two were from SAGE (Faculty of Science, Agriculture and Engineering), including one from the School of Chemical Engineering (CEM) and one from the School of Computer Science (CS). BUSI and EDUA were studied in both 2010-2011 (phase I) and 2011-2012 (phase II), while the other three modules were just accessed in phase II. Staff had different understandings and different aims in using PA, and thereby they used various procedures.

Classification (C-) and framing (F-) was weak in the three modules from HASS. Especially in EDUA, the module leader recommended some articles of PA to students, gave them space and enabled them to explore and understand by themselves. The strength of social rules between the module leader and students was not tight in that he saw his position as a supporter rather than an authority and students had more apparent control during the process. However, ISs in these three modules had different understandings of the F- context. Some highly appreciated this style, as they had the chance to enjoy self-learning, as a Vietnamese student (female, EDUA, phase II) said: 'You really have power to decide what you do (in PA)... you can be responsible for yourself...'. While others were sometimes confused when they lacked strict instructions, for they did not adjust well to the student-centred situation, as a Chinese student (female, EDUA, phase II) said: 'In China, it's a teacher-centred classroom, I was worried I might get lost if there were few sessions in the UK, no direction, I much preferred to follow teachers' instruction'.

Table 1. The use of PA in the five modules (1).

\begin{tabular}{|c|c|c|c|c|}
\hline \multicolumn{2}{|c|}{ Disciplines } & \multirow{2}{*}{$\begin{array}{l}\text { Mark \& } \\
\text { Feedback }\end{array}$} & \multirow{2}{*}{$\begin{array}{l}\text { Value at the } \\
\text { final mark }\end{array}$} & \multirow{2}{*}{$\begin{array}{l}\text { Anonymity } \\
\text { YES }\end{array}$} \\
\hline \multirow{3}{*}{ HASS } & BUSI & & & \\
\hline & EDUA & $\mathrm{F}$ & $0 \%$ & NO \\
\hline & EDUB & $\mathrm{F}$ & $0 \%$ & NO \\
\hline \multirow{2}{*}{ SAGE } & CEM & $\mathrm{M}+\mathrm{F}$ & $30 \%$ & YES \\
\hline & $\mathrm{CS}$ & $\mathrm{M}$ & $25 \%$ & YES \\
\hline
\end{tabular}

Table 2. The use of PA in the five modules (2).

\begin{tabular}{llll}
\hline \multicolumn{2}{c}{ Disciplines } & $\begin{array}{l}\text { Formative/Summative } \\
\text { assessment }\end{array}$ & $\begin{array}{l}\text { Classification \& } \\
\text { Framing }\end{array}$ \\
\hline \multirow{3}{*}{ HASS } & BUSI & F (Phase I) S (Phase II) & C-, F- \\
& EDUA & F & C-, F- \\
& EDUB & F & C-, F- \\
\multirow{2}{*}{ SAGE } & CEM & S & C,+ F+ \\
& CS & S & $\mathrm{C}+$, F+ \\
\hline
\end{tabular}

Classification $(\mathrm{C}+)$ and framing $(\mathrm{F}+)$ was strong in the two modules from SAGE. Pedagogic discourses by the two module leaders were not very flexible as they always provided standard answers. The social rules between staff and students were strong. For instance, when talking about discourse between staff and students, the module leader in CEM had an entirely different view from the module leader in EDUA, as she said: 'I think students need to see you as an authority in the field. I don't mean you have to do what I say but I'm expert in the field, earn students' respect. Then the discussion between us could be much easier'. Relatively, students in these two modules tended to pursue specific correct answers expected by staff. Even when students implemented PA which to some extent empowered them autonomy, they still relied on staff. Thus, PA has more summative characteristics in these two modules.

Studies illustrate that by addressing diverse aims, assessment practice in $\mathrm{HE}$ can sometimes correspond to assessment policy, but sometimes they can also be incongruous [13-14]. Thus, hearing views from assessment policy makers can provide us with an important perspective on assessment practices. In this study, an assessment policy maker at this university expressed her attitude towards assessment in HE. The university provides an assessment policy to inform both staff and students that the university does not only rely on assessment to make selection decisions or grant degrees to students, but also addresses assessment to affect students' approaches to learning, such as how they utilize feedback for future learning and develop lifelong learning skills. ISs are currently a focus to be addressed when policy makers are revising assessment policy. Thus, the university has already recognised the existence of ISs, as she commented: 'That's one thing that came out from our conversations, like whether we should have or not have 
special assessment policies on ISs, like if we should have guidelines on how to adjust ISs, whose English is not as good as others, how to manage that...'. However, policy makers have not made any final decision yet, and it is significant for them to understand how ISs are influenced by assessment.

To avoid contradictions between policy and practice, the university leaves enough space for module leaders to design assessment approaches, but particularly recommends formative assessment, which is in accordance with the current assessment literature. She commented: 'I think module leaders have quite a lot of room in our university. There are certain guide lines like how long assessment can be... but in terms of personal preference, if they prefer exams...essays... or PA... there is definite flexibility. We want people to know there is flexibility, especially the use of formative assessment, how they use it, why they use it...I will recommend formative assessment, but also make staff and students aware how many forms there are, because some students may think formative assessment is just a conversation with their module leader. But it's an assessment in its own way. It's not just guidance...we are trying to make many examples...'

Formative assessment has the potential to develop learner autonomy and foster lifelong learners, both of which are essential purposes of HE [15]. Assessment policy makers and qualification designers are increasingly interested in encouraging deeper engagement with learning and enhancing autonomy brought about by formative assessment [16]. This university is following the trend and revising assessment policy to promote the use of formative assessment across departments. Results suggest that using a 'bottom-up' mode to implement the reform allows staff to create their own approaches and to make changes, which is important to promote the reform policy [17]. The policy maker explained that the revision of assessment policy aims to encourage staff rather than force them to use formative assessment, so in the policy documents there are some definitions and guidelines on formative assessment, along with examples of successful practices.

Meyer, et al. propose that university assessment policy is unlikely to cover every contingency, situation or preference [16]. 'Rules and regulations to ensure consistency across offerings may provide quality assurance', argued by Craddock and Mathias [16], 'but are also likely to constrain the use of diverse assessment practices shown to have a positive impact on student learning'. At the university level, policy makers do not intend to give strict rules of assessment methods or specific procedures, but provide space for teaching staff to design assessment procedures themselves to fit their own needs. Furthermore, the university holds workshops and conferences to disseminate revised assessment policy, and provides staff education on formative assessment and feedback. The networks, including support from university and faculty, provide a source of legitimacy for staff innovation. This strategy created the possibility for staff to assert their own beliefs in the interpretation of the policy into classroom practice. Currently, the university is trying to promote formative assessment across disciplines, and the five modules in this study represent this tendency. The university's empowerment of staff made it possible for them to participate in the design of formative assessment rather than simply reproduce assessment methods, so that staff can be more positive and empowered by reform [18].

The staff professional development program in the university offers a workshop 'formative assessment' to staff to promote this kind of assessment, in accordance with the dissemination of university assessment policy. A staff educator was interviewed in this study, and she expressed her attitudes towards feedback, formative assessment and teaching ISs. In the workshop, the staff educator explicitly addressed feedback. She suggested that tutors do not only give feedback to students to improve their work, but also to encourage feedback from students to demonstrate their reflections, so feedback could go to both sides. One module leader in CEM mentioned she would like to look at students' peer feedback and then reflect on her teaching: 'I will see how they look at each other and I'm thinking how I may comment on the same work. Maybe I miss something that they frankly point out, then I will remind myself'.

The staff educator tries to blur boundaries between different subjects in order to promote staff cooperation and facilitate the experience of learning from each other before they encourage students to do so. She supported the C- and F- context, as she said: 'In the workshop, teachers come from across disciplines. They may have quite different knowledge backgrounds, but like teachers from dentistry may learn something from teachers from chemistry'. The staff educator holds the same opinion as the module leader in EDUA that talking is important in the learning process, so both of them prefer to encourage talk either among peers or between staff and students: 'Encouraging tutors to talk and discuss in the workshop is a good approach to making them feel formative learning first'. However, this innovative approach is not widely used in the university at the moment, as she commented: 'I think it's not widely seen across the university...Staff particularly prefer to do summative assessment, give marks anonymously...I know one or two people are doing this in postgraduate programme in HASS, encouraging discourses between tutors and students, especially to ISs, using discussion as part of feedback'.

Regarding the promotion of formative assessment through assessment policy, the staff educator supposes that there is a gap in understanding about feedback between staff and students in practice, as she said: 'I suppose every member of staff would say they do formative assessment, but if I ask the students, they may say no sometimes'. Indeed, this is also the reason that policy makers are revising university assessment policy at the moment. They hope that not only staff, but also students understand assessment policy. When both staff and students share the same understanding of assessment, particularly formative assessment, then this form can become popular and effective in the university. Otherwise, students may not emphasize it, as a UK student (female, EDUA, phase I) said: 'I think the tutor should explain benefits, 
objectives and purposes of using PA, otherwise students will not take it seriously'.

In Robson, et al.'s research, some ISs in postgraduate taught modules reflected that the master programme was just one year, and after they understood learning and feedback they return to their home contexts [19]. The staff educator assumed that UK students have similar perceptions of formative assessment and feedback as ISs who do not know how to use feedback for improvement of learning, as she commented: 'Quite a few UK students just recognize written comments, if feedback is not written like that, it's not feedback...I don't think UK students know what to do with it (feedback)'. Offering students the opportunity to receive appropriate feedback for their learning needs is suggested when staff design assessment [20]. More importantly, students need to be empowered to recognize feedback and learn how to make use of it [21]. As long as staff and students share the same understanding of formative assessment, both sides may appreciate its benefits.

\section{Discussion}

Many universities are now redesigning curricula in order to adapt for internationalization [3]. This study has investigated postgraduate ISs' experiences of PA, and heard the voices of teaching staff, university assessment policy maker and staff educator, and thereby has an insight into the current progress of the internationalization in this university. Since staff are key agents in the implementation of the international strategy of universities [4], based on the findings in this study, there are some suggestions for staff to teach and assess ISs.

(1) In this diverse and highly competitive HE climate, it is important that teaching practices are reviewed 'to educate from, with, and for a multitude of cultural perspectives' [4] to ensure a high quality student experience. The internationalization of HE has seen increasing numbers of ISs come to the UK to undertake postgraduate studies. For students from other contexts or cultures, approaches to postgraduate study in the UK may contrast with their earlier experiences of learning, such as structured learning in contrast with independent learning and reproductive behaviour in contrast with critical thinking [4]. Actually, some academic approaches taken for granted by staff may be unfamiliar for ISs (ibid). For example, some staff imagined that ISs should be familiar with PA, whereas this study has found that PA was almost unknown to many of ISs. Staff's own context or culture may lead ISs to misunderstand their intentions of specific pedagogic activities, and thereby students may lose the chance to perform well.

With regard to assessment, it is especially important for those ISs whose previous experiences are culturally distant from those of the assessors. As Ryan and Carroll point out, during assessment staff might encounter unanticipated or surprising behaviours from ISs due to cultural differences, such as different expectations between students and staff about what is required and different views of respect for the authoritative nature in assessment [22]. Although staff cannot change learners' prior experiences of assessment, they can deploy agency to make creative and reflexive response to cultural differences in the classroom, share students' recognition and realization rules, and design a culturally inclusive assessment for students.

(2) Brown suggests that we can use self-assessment [11], PA and group assessment, which are very effective in helping students interpret criteria, encouraging students' metacognition, and encouraging deep rather than surface learning. However, some studies report that students gain greater learning from staff feedback than from self- and peer feedback [23]. Referring to PA, Kauffman and Schunn highlight staff feedback along with peer feedback [24]. Hence, it would be beneficial that staff explicitly discuss and exemplify the value and relevance of PA to future tasks before PA and have constructive talks with students about feedback after PA. In addition, staff who are interested in empowering students may find that it is particularly helpful to focus on the process of formative assessment and use dialogic talk [9].

(3) Irrespective of disciplines, group work has been considered an effective strategy to support learning and can also develop the generic team working skills that are highly valued by employers, so this pedagogic activity is very popular in UK HE [25]. Strang finds that ISs are likely to achieve more highly in western academic settings if they favour group work, risk taking and interactive learning [26]. In this study, some ISs described their transition from disliking group work to favouring this style, as did a Chinese student (male, CS, phase II), who changed his attitude towards group work after conducting PA: 'When I meet team work next time...I will be more willing and well prepared to engage in the team, and won't fear it any more'. ISs may have limited recognition and realization rules for the western academic setting in the beginning, but they can perceive the classroom culture after a period of studying with effective tools. Encouraging ISs to join group work can be an initial method to help their adjustment to learning in the UK.

However, not all ISs experience such a positive transition. Edmead points out that the reason students do not favour group work in the international classroom always refers to a lack of preparation for group work, a lack of awareness of the benefits of studying in a multicultural context, or a lack of clarity of the learning outcomes of this activity [25]. With regard to organized groups, some may be comprises of students from the same context, while others may be comprised of students from mixed contexts. Caruana and Ploner suggest that an internationalized curriculum should encompass all students from diverse backgrounds and provide space to discuss and reflect differences [2]. Thus, it is vital to organize multicultural groups if we expect to foster intercultural communication and develop intercultural competence during group work. The current study suggests different combinations of group members each time and English as the sole medium in group communication so that all students can collaborate with others from various contexts. 


\section{Conclusion}

To internationalize the curriculum, we need innovative academic approaches to intercultural learning for students in both formal and informal learning experiences and assessment practices. This study has pointed out an innovative assessment approach that has the potential to contribute to personal development and intercultural learning However, there are some practical issues to consider and not all users can achieve the expected learning outcomes, especially when staff and students have little awareness of intercultural learning. If one purpose of undertaking PA is for students to develop intercultural competence, then this should be more explicitly outlined in the learning outcomes of the exercise, so that all agents in the international classroom can share this message. This rule also applies to other pedagogic activities that aim at internationalizing the curriculum. Moreover, we argue that staff agency in regard to internationalisation will depend a great deal on the environment that either constrains or encourages them. Thus, we almost certainly need a 'spurt' of encouragement in UK HE to get staff to rethink some of the dimensions of teaching groups with international students involved. Future studies may explore different strategies when there are a minority of international students and when there is a majority, which is not uncommon in postgraduate taught modules.

\section{Acknowledgements}

This research received financial support from the Research Project for Young Teachers of Fujian Province (No. JAS160071), and Scientific Research Foundation of Fuzhou University (No. XRC201515).

\section{References}

[1] K. J. Topping, Peer Assisted Learning: a Practical Guide for Teachers. Cambridge MA: Brookline Books, 2000.

[2] E. Jones, 'Internationalization and employability: the role of intercultural experiences in the development of transferable skills', Public Money and Management, 33(2), 2013, pp. 95-104.

[3] J. Ryan, (ed.) Cross-cultural Teaching and Learning for Home and International Students: Internationalization of Pedagogy and Curriculum in Higher Education. Oxon; New York: Routledge, 2013.

[4] S. Robson, 'Internationalization: a transformative agenda for higher education?', Teachers and Teaching, 17(6), 2011, pp. 619-630.

[5] R. Barnett, A Will to Learn, Being a Student in an Age of Uncertainty. Berkshire: Society for Research into Higher Education and Open University Press, 2007.

[6] J. B. Beckwith, 'Approaches to learning, their context and relationship to assessment performance', Higher Education, 22(1), 1991, pp. 17-30.

[7] S. Kvale, 'Contradictions of assessment for learning in institutions of higher learning, in Boud, D. and Falchnikov, N. (eds.) Rethinking Assessment in Higher Education: Learning for the Longer Term. New York and Milton Park: Routledge, 2007, pp. 57-71.

[8] D. Boud, R. Cohen and J. Sampson, 'Peer learning and assessment', in Boud, D., Cohen, R. and Sampson, J. (eds.) Peer Learning in Higher Education. London: Kogan Page, 2001, pp. 67-81.

[9] M. Fan, S. Robson and D. Leat, International Postgraduate Students' Perceptions and Experiences of Peer Assessment in a UK University: A Case Study. In Gordon Slethaug and Jane Vinther (eds) International Teaching and Learning at Universities, 2015, pp. 135-158. New York: Palgrave Macmillan.

[10] C. Evans, 'Making sense of assessment feedback in Higher Education', Review of Educational Research, 83(1), 2013, pp. 70-120.

[11] Brown, S. 'Assessment for learning', Learning and Teaching in Higher Education, 5(1), 2004, pp. 81-89.

[12] S. Tang and A. Chow, 'Communicating feedback in teaching practice supervision in a learning-oriented field experience assessment framework', Teaching and Teacher Education, 23(7), 2007, pp. 1066-1085.

[13] C. Leathwood, 'Assessment policy and practice in higher education: purpose, standards and equity', Assessment and Evaluation in Higher Education, 30(3), 2005, pp. 307-324.

[14] D. Carless, G. Joughin and M. Mok, 'Learning-oriented assessment: principles and practice', Assessment and Evaluation in Higher Education, 31(4), 2007, pp. 395-398.

[15] M. Yorke, 'Formative assessment in higher education: moves towards theory and the enhancement of pedagogic practice', Higher Education, 45(4), 2003, pp. 477-501.

[16] L. Meyer, S. Davidson, L. McKenzie, M. Rees, H. Anderson, R. Fletcher, et al. 'An investigation of tertiary assessment policy and practice: alignment and contradictions', Higher Education Quarterly, 64(3), 2010, pp. 331-350.

[17] C. Wallace, and M. Priestley, 'Teacher beliefs and the mediation of curriculum innovation in Scotland: a socio-cultural perspective on professional development and change', Journal of Curriculum Studies, 43(3), 2011, pp. 357-381.

[18] M. Schmidt, and A. Datnow, 'Teachers' sense-making about comprehensive school reform: the influence of emotions', Teaching and Teacher Education, 21(8), 2005, pp. 949-965.

[19] S. Robson, D. Leat, K. Wall and R. Lofthouse, 'Feedback or feed forward? Supporting Master's students through effective assessment to enhance future learning', in Ryan, J. (ed.) Cross-cultural Teaching and Learning for Home and International Students: Internationalization of Pedagogy and Curriculum in Higher Education. Oxon; New York: Routledge, 2013, pp. 51-68.

[20] P. Knight and M. Yorke, Learning, Curriculum and Employability in Higher Education. London: Routledge. 2003.

[21] Poulos, A. and Mahony, M. J. (2008) 'Effectiveness of feedback: the students' perspective', Assessment and Evaluation in Higher Education, 33, pp. 143-154. 
[22] Ryan, J. and Carroll, J. (2005) "“Canaries in the coalmine": international students in Western universities', in Carroll, J. and Ryan, J. (eds) Teaching International Students: Improving Learning for All. Abingdon: Routledge, pp. 3-10.

[23] Chang, N. (2011) 'Pre-service teachers' views: how did e-feedback through assessment facilitate their learning?', Journal of the Scholarship of Teaching and Learning, 11, pp. 16-33.

[24] Kauffman, J. and Schunn, C. (2011) 'Students' perceptions about peer assessment for writing: their origin and impact on revision work', Instructional Science, 39, pp. 387-406.
[25] Edmead, C. (2013) 'Capitalising on a multicultural learning environment: using group work as a mechanism for student integration', in Ryan, J. (ed.) Cross-cultural Teaching and Learning for Home and International Students: Internationalization of Pedagogy and Curriculum in Higher Education. Oxon; New York: Routledge, pp. 15-26.

[26] Strang, K. D. (2011) 'Global culture, learning style, and outcome: an interdisciplinary empirical study of international university students', Intercultural Education, 21(6), pp. 519-533. 